\title{
Aprendizagem ativa e deeper learning: reflexões sobre as demandas por uma educação em compasso com seu tempo
}

\author{
Active learning and deeper learning: reflections on the demands for an \\ education in line with the real world
}

Bruno Gomes de Almeida

Doutor na Universidade do Estado do Rio de janeiro, Rio de Janeiro, Brasil. brugomes7@yahoo.com.br - https://orcid.org/0000-0003-3317-7040

Recebido em 23 de fevereiro de 2019

Aprovado em 30 de outubro de 2019

Publicado em 27 de julho de 2020

\section{RESUMO}

Considerando a tendência crescente por renovação das práticas pedagógicas na educação, a ideia de "ativação" dos estudantes tem se tornado uma concepção-chave nessa discussão. Desta forma, o texto apresenta uma reflexão sobre o que, de fato, tem fundamentado essa noção, contextualizando a questão a partir das demandas cada vez maiores por uma educação mais em compasso com seu tempo. Sistemas educacionais capazes de atender às urgências da contemporaneidade, sobretudo, através de reconfigurações que levem em conta: as pesquisas e teorias científicas do campo dos estudos da aprendizagem; as demandas do mundo produtivo e do trabalho; e as demandas advindas de complexas questões sociais. Assim, é apresentado o conceito de deeper learning como um exemplo de tentativa em transpor para as práticas pedagógicas as demandas de uma educação que se quer promotora do que comumente tem se denominado "aprendizagem ativa", acima de tudo, um processo de aprendizagem mais conectado à realidade cotidiana. A partir deste objetivo, são discutidos alguns conceitos e termos que ajudam a contextualizar a discussão de maneira mais ampla, tendo como foco central o campo da educação, como os casos de: "sociedade do conhecimento", "sociedade da aprendizagem" e "competências do século XXI".

Palavras-chave: Aprendizagem ativa; Deeper learning; Sociedade da aprendizagem.

\section{ABSTRACT}

Taking into account the growing tendency towards pedagogical practices renovation in education, the idea of "activated student" has became a key concept in this discussion. Thus, the text presents a reflection on the basis of this notion, contextualizing the issue from the increasing demands for a education in line with the real world. Educational systems capable of dealing with the urgencies of contemporary 


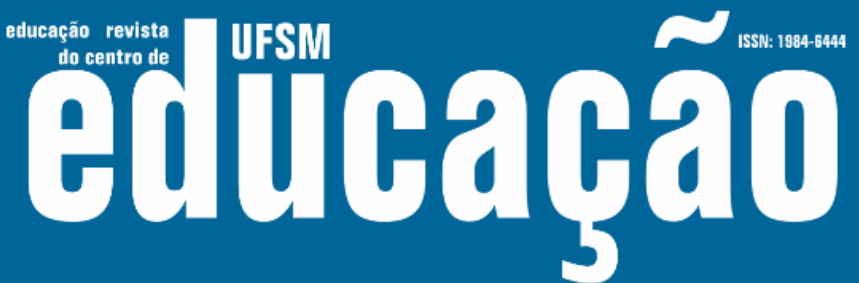

ISSN: 1984-6444 | http://dx.doi.org/10.5902/1984644437035

world, especially, reorienting themselves considering: scientific researches and theories from the field of the learning studies; the working world demands; and the complex cultural and social demands. In this way, it is introduced the concept of "Deeper learning" as an effort to take to pedagogical practices the demands related to an education interested in promoting what is usually called "active learning", above all, a learning process more connected to the real world. From this perspective, were discussed the roles of some concepts and terms that contribute to put in a social context the educational field, the cases of: "Knowledge Society", "Learning Society" and "21st Century Competencies".

Keywords: Active Learning; Deeper learning; Learning society.

\section{Introdução}

Nos últimos anos, tem se disseminado no meio educacional, cada vez mais, discussões sobre a necessidade de se pensar alternativas para as salas de aula tradicionais. O diagnóstico do crescente desinteresse, desmotivação e desatenção dos estudantes de hoje dia junta-se à evidência de que as estratégias pedagógicas de maior eficácia em termos de aprendizagem e desenvolvimento são aquelas que criam circunstâncias efetivas para que os educandos sejam mais "ativos".

Em 2000, o PISA (Programme for International Student Assessment), sistema criado pela OCDE (Organização para a Cooperação e Desenvolvimento Econômico) para a realização de um processo internacional de avaliação da educação básica, colocou em prática o seu primeiro programa de avaliação. Logo em sua primeira edição houve uma grata surpresa entre os países líderes dos rankings: a Finlândia. Este pequeno país escandinavo de aproximadamente 5,3 milhões de habitantes sequer era postulado como uma das melhores referências em qualidade de educação básica no mundo. Fato que, consequentemente, fez com que os olhos do mundo voltassem-se para o seu modelo de educação.

A partir de então, descobriu-se que, entre outras particularidades, o redesenho da experiência educacional com foco, sobretudo, em maior autonomia e personalização, era um dos principais diferenciais da educação finlandesa. Uma educação, acima de tudo, interessada em transformar os estudantes em agentes ativos de seus processos de aprendizagem. Algo que se disseminou pelo mundo da educação, estabelecendo-a como um dos principais paradigmas da ideia de 


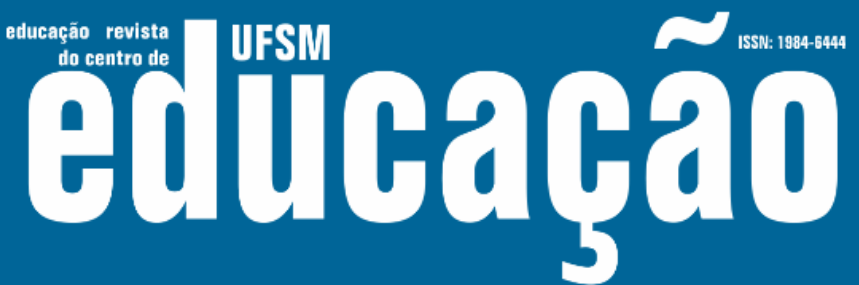

ISSN: 1984-6444 | http://dx.doi.org/10.5902/1984644437035

renovação de práticas pedagógicas. Embora a história da educação já ofereça há tempos um grande leque de exemplos de educadores e pensadores precursores dessa noção de que a aprendizagem precisa ser um processo ativo. John Dewey, Paulo Freire, ou mesmo Eurípedes Barsanulfo, são alguns desses nomes.

Mas, para se entender a relevância de uma sala de aula que "ative" seus estudantes, é preciso compreender o contexto em que surge esta demanda. Conhecer as razões pelas quais tanto se fala da necessidade de uma educação cada vez mais em compasso com seu tempo.

Desta forma, é apresentada uma reflexão que esboça em linhas gerais algumas das evidências de que o mundo globalizado cria circunstâncias que precisam ser mais consideradas pelos sistemas educacionais. Uma maior conexão entre o que se estuda e o que se vivencia na vida real.

Por isso, é trazido à tona termos e conceitos que ajudam a delinear um horizonte de análise que facilite a compreensão das razões que fundamentam essas discussões no universo da educação. Casos de: "mundo globalizado"; "sociedade do conhecimento"; "sociedade da aprendizagem"; "competências do século XXI"; "aprendizagem ativa"; e deeper learning.

\section{Mundo, sociedades e educação}

Imaginar o papel estratégico que uma cidadezinha espanhola de aproximadamente 3 mil habitantes pode ter nesse mundo de intensa comunicação, fluxos contínuos de informação e de pessoas, pode não ser tarefa fácil. Zamudio, localizada na província de Biscaia, na comunidade autônoma do País Basco, Espanha, não costuma ser uma localidade muito presente nos roteiros turísticos daqueles que se aventuram por terras espanholas. Sua notoriedade deve-se muito mais a outras razões. Pois é lá que a Gamesa Corporación Tecnológica tem a sua sede principal. Uma multinacional espanhola do setor de tecnologia e engenharia aeroespacial. Empresa com uma atuação a nível global, tal qual a belga Sonaca e a estadunidense General Eletric. Ambas com suas sedes matrizes em Gosselies e Boston, respectivamente. Uma pequena vila do município de Charleroi, situado na 


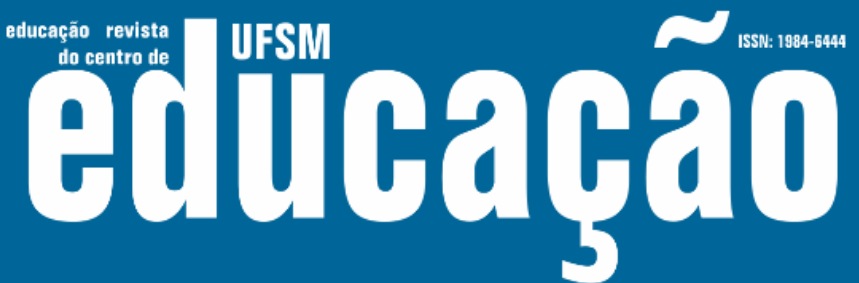

ISSN: 1984-6444 | http://dx.doi.org/10.5902/1984644437035

região de Valónia, na Bélgica, com pouco mais de 11 mil habitantes, contrastando com a capital do estado de Massachusetts, um dos centros metropolitanos mais populosos dos Estados Unidos, com quase 6 milhões de pessoas. Três cidades bastantes distintas entre si, seja pela cultura ou pela quantidade de residentes. Contudo, interligadas em razão de pertencerem a uma cadeia produtiva única.

As fuselagens traseiras da Gamesa, os pilones da Sonaca, assim como, o sistema de propulsão da General Eletric, são componentes fundamentais presentes nos aviões montados pela brasileira Embraer. Três exemplos de outros que poderiam ser apresentados e que atestam o quanto o mercado global encontra-se transnacionalizado. Um produto construído por uma empresa local é derivado de uma complexa cadeia produtiva segmentada por equipamentos provenientes de diversas partes do mundo. Efeito de uma demanda cada vez maior por inovação e otimização produtiva, acarretando em um sistemático processo de importação de insumos tecnológicos. Um exemplo patente do quanto os mercados estão interligados hoje em dia.

A indústria aeronáutica fomenta um dos segmentos de mercado mais importantes da economia mundial. Não é para menos, afinal, trata-se de um ramo em que seus "produtos" oscilam facilmente entre valores exorbitantes. Cifras que se iniciam em $\mathrm{R} \$ 16$ milhões, no caso de jatos de pequeno porte, podendo chegar a números astronômicos que superam $R \$ 1$ bilhão. Um setor que movimenta não só um grande número de pessoas, mas também um grande volume de dinheiro.

Em meados dos anos 1960, o rápido avanço de tecnologias de comunicação e de transporte já causava certo sobressalto em razão de sua magnitude. Na época, a difusão das linhas telefônicas e do transporte aéreo pelo mundo insinuavam uma impressão que, com o passar das décadas, resultou em certezas inevitáveis. 0 alcance praticamente irrestrito de informação sobre os quatro cantos do planeta trouxe à tona a sensação de uma interligação total entre os povos e os países. Tanto que, algumas metáforas tornaram-se paradigmáticas ao tentarem retratar o estado das coisas. "Aldeia global" foi uma delas. O filósofo canadense Marshall McLuhan (McLUHAN; FIORE. 1971) cunhou este termo para esboçar certo diagnóstico desse contexto. O mundo enquanto uma aldeia, tal qual as aldeias indígenas, compostas por 


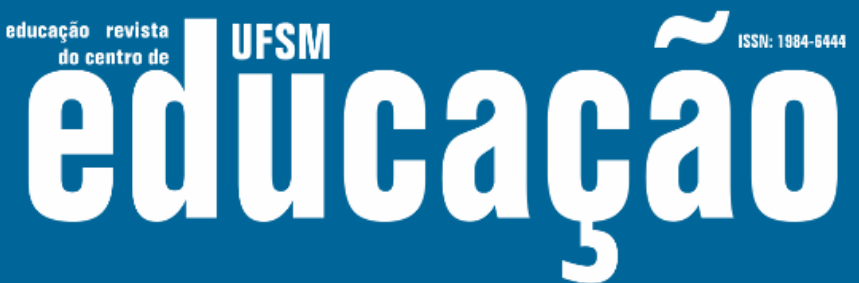

ISSN: 1984-6444 | http://dx.doi.org/10.5902/1984644437035

várias ocas ao redor umas das outras, em proximidades que facilitam as trocas e os fluxos de informação.

Com o passar dos tempos, a ideia da existência de uma verdadeira sociedade global consolidou-se frente ao ininterrupto aprimoramento da tecnologia e da crescente complexidade e amplitude das trocas comerciais entre os países. Circunstâncias que ajudaram a firmar a noção de globalização como uma espécie de lógica econômica, social e cultural que passou a reger a humanidade.

O fato é que o mundo globalizado estabelece um nível de complexidade para a vida, que, inevitavelmente, faz brotar a necessidade do surgimento de formas de se lidar com as demandas insurgentes, Sobretudo, as suas complexidades e contradições inerentes.

\begin{abstract}
A mundialização e a globalização são acompanhadas por processos opostos, como a dominação e a solidariedade; as ondas democratizadoras e os fanatismos; as ondas liberalizadoras e os ditames do mercado; as homogeneizações e padronizações culturais conforme os modelos norteamericanos e as resistências e revitalizações das culturas autóctones; e ainda a miscigenação cultural. (MORIN; DÍAZ, 2016, p.10)
\end{abstract}

Desta forma, o diagnóstico acima releva alguns dos aspectos que envolvem esta complexidade. $\mathrm{O}$ que faz com que determinadas habilidades e competências sejam fundamentais para lidar com este cenário.

Muito já se discutiu sobre como seria possível classificar esse estágio de desenvolvimento marcadamente globalizado. Termos como "sociedade industrial", "sociedade pós-industrial" e "sociedade do conhecimento" passaram a ser utilizados com certa recorrência para caracterizar as diferentes fases pelas quais a humanidade tem passado nos últimos tempos. Especificamente, a "sociedade do conhecimento", definição mais próxima do contexto atual, embora um conceito com definição e implicações não tão claras, tornou-se uma maneira de denominar um contexto em que as sociedades, após acumularem diversas ferramentas de busca e de produção de informação, valorizam o conhecimento como a força motriz de sua própria transformação. Condição já enunciada por certos autores há alguns anos, casos de Robert Lane (1966), Daniel Bell (1973), Peter F. Drucker (1976), 


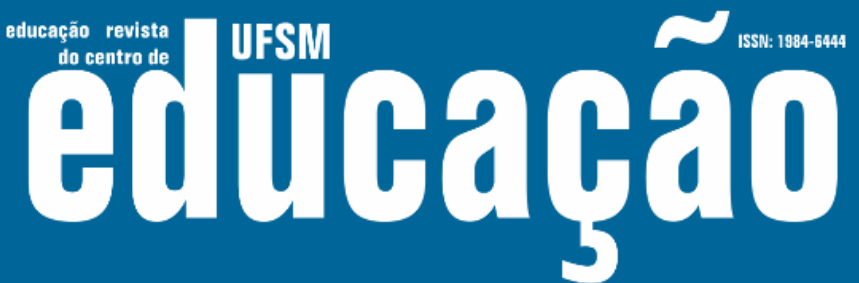

ISSN: 1984-6444 | http://dx.doi.org/10.5902/1984644437035

Manuel Castells (2010), entre outros. A propósito, uma discussão que, ultimamente, tem oscilado bastante entre uma visão mais otimista ou uma visão mais crítica da "sociedade do conhecimento".

Embora haja bastante reflexões sobre a pertinência deste termo, sobretudo, em razão de sua pressuposta generalização excessiva na visão de alguns autores, o que nos cabe é uma atenção sobre como esta ideia acerca da sociedade do conhecimento tem se desdobrado ultimamente. Já que, principalmente, sob a perspectiva da educação, as sociedades globalizadas atuais trazem à tona demandas para além do diagnóstico do excesso de oferta de conhecimento. Há uma urgência para se conceber formas cada vez mais aprimoradas de lidar com ele, de gestão desse conhecimento. E isso, inevitavelmente, lança luz sobre a questão da aprendizagem.

Posto que as sociedades globalizadas alcançaram um alto grau de compartilhamento de informação, de trocas comerciais e culturais, além de uma forte interdependência mercadológica, tem-se um cenário bastante multifacetado. Novas demandas e contradições sociais, culturais e econômicas insurgindo a todo momento.

Desta forma, em discussões recentes sobre temáticas que envolvem sociedade, educação e trabalho, tem ganhado força a utilização do termo "sociedade da aprendizagem". Algo que surgiu quase como uma consequência de todo contexto transformativo enunciado pela denominada "sociedade do conhecimento". Embora ainda haja a necessidade de maior clareza na diferenciação entre os termos na literatura especializada.

Em seu livro O Ensino na Sociedade do Conhecimento - a educação na era da insegurança (2004), Andy Hargreaves apresenta um entendimento interessante dessas questões. Para ele, na verdade, o termo ideal para retratar o mundo atual não seria exatamente "sociedade do conhecimento", mas sim, "sociedade da aprendizagem". Afirma que os processos de produção de conhecimento das sociedades são dependentes da capacidade de seus integrantes em adaptarem-se às transformações de modo a conceber a aprendizagem de forma autônoma e contínua em suas vidas. Uma concepção que deriva do conceito de lifelong learning (FISHER, 2000), "aprendizagem ao longo da vida". A noção de que, cada vez mais, as 


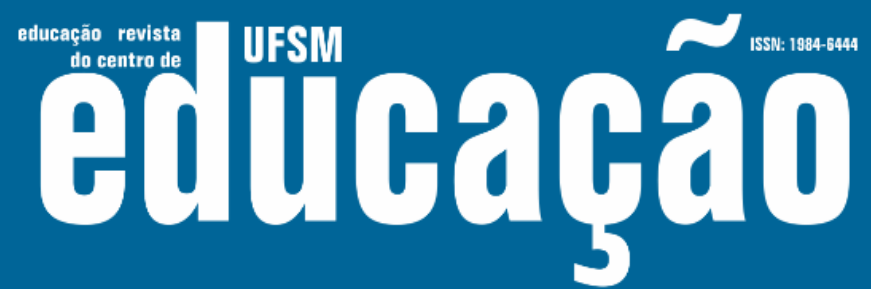

ISSN: 1984-6444 | http://dx.doi.org/10.5902/1984644437035

sociedades têm demandado de seus membros um irrestrito interesse por aprender, por incorporar a sua lógica transformadora e transformativa ao longo de toda a vida. Uma sociedade em constante transformação requer um sujeito em constante formação.

Todas as sociedades - aquelas com populações envelhecidas ou aquelas com uma juventude iminente - necessitarão de mais pessoas economicamente ativas ao longo da vida. Isto é algo que não apenas demanda uma infra-estrutura para a aprendizagem ao longo da vida, mas também, um renovado e replanejado investimento nos primeiros anos da aprendizagem. É fundamental que estes anos estabeleçam fortes alicerces para o conhecimento futuro e estimulem um amor pelo "aprender" que irá motivar as pessoas para a jornada de aprendizagem que terão pela frente. (CISCO, 2010, p.6)

Sob o ponto de vista econômico, a iminência da "sociedade da aprendizagem" poder ser pensada como uma consequência da própria tendência de envelhecimento da população, sobretudo, em países desenvolvidos e emergentes. As constantes transformações no mundo do trabalho, associadas ao aumento da longevidade, criam novas circunstâncias para a vida produtiva. A necessidade de renovação e requalificação profissional contínuas será uma exigência cada vez mais inelutável.

O crescente protagonismo do setor de serviços no mundo (AREND; GIOVANINI, 2017), sobretudo, no Brasil, atesta ainda mais a necessidade de nos atentarmos para as demandas da "sociedade da aprendizagem". É um setor que tem solicitado, cada vez menos, um trabalho rotineiro, repetitivo e segmentado, e cada vez mais um trabalho inventivo, colaborativo e autônomo.

\footnotetext{
Economias industriais baseadas nos princípios de produção em massa demandaram um grande número de pessoas com níveis básicos de formação educacional e um pequeno número de especialistas com habilidades mais aprofundadas. Hoje em dia, a redistribuição da produção, a automação, a customização em massa e a especialização flexível demandam um novo tipo de educação e um novo tipo de aprendizagem. Encarar estes desafios significa repensar o papel de cada setor da sociedade - Estado, negócios, família e sociedade civil - tanto quanto redesenhar os nossos sistemas de educação formal. (CISCO, 2010, p.21).
} 


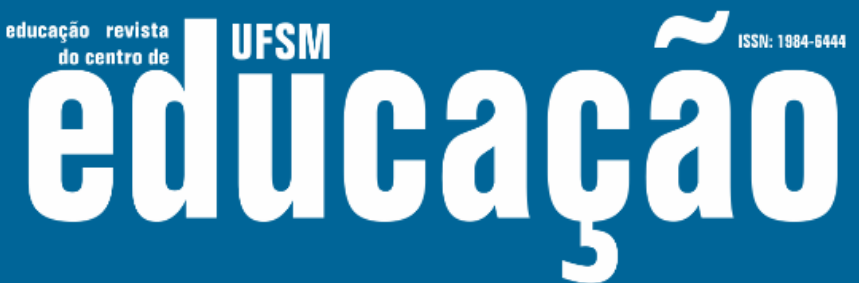

ISSN: 1984-6444 | http://dx.doi.org/10.5902/1984644437035

Desta forma, a passagem acima evidencia o quanto a educação precisa se inserir nessa discussão. Repensar a forma de fazer educação é uma das coisas mais urgentes a serem postas em prática no mundo contemporâneo.

Em 1996, a "Comissão internacional sobre educação para o século XXI" publicou um relatório para a UNESCO sob o título Educação: um tesouro a descobrir. Este documento prenunciava algumas das direções e demandas mais importantes para se pensar uma educação, de fato, em compasso com seu tempo. Uma educação capaz de abarcar os desafios que se apresentavam de um mundo global em constante transformação. Em seu conteúdo, é destacável o que foi denominado como sendo "os quatro pilares fundamentais da educação do século XXl": aprender a conhecer; aprender a fazer; aprender a conviver; aprender a ser.

"Aprender a conhecer" refere-se à aquisição de capacidades cognitivas e metacognitivas. Desenvolver o pensamento crítico, capacidade analítica, capacidade criativa e aprender a aprender são algumas das questões que se destacam. Em "aprender a fazer", em suma, é enfatizado a capacidade de colocar na prática o conhecimento teórico. Já "aprender a conviver" envolve condições comportamentais, especialmente, agir e trabalhar colaborativamente. E "aprender a ser" apresenta um pilar relacionado à construção de uma personalidade capaz de agir de forma equilibrada, com autoconhecimento, competências socioemocionais e responsabilidade pessoal e social.

Deste modo, percebe-se que o fato de cada um dos quatro pilares serem apresentados a partir da premissa do "aprender" traz uma evidência interessante. Atrelar o verbo "aprender" antes das competências que compõem os quatro pilares realça o seu protagonismo no contexto atual. Afinal, uma educação que se quer transformadora necessita, acima de tudo, priorizar a aprendizagem enquanto foco principal da ação educadora. Essa noção alarga-se, principalmente, se pensarmos que o mundo contemporâneo tem sido concebido muito mais como cenário para "sociedades da aprendizagem", como destacado anteriormente. Em outras palavras, o foco no "aprender" gera uma atenção mais minuciosa para com os processos de construção do conhecimento. 


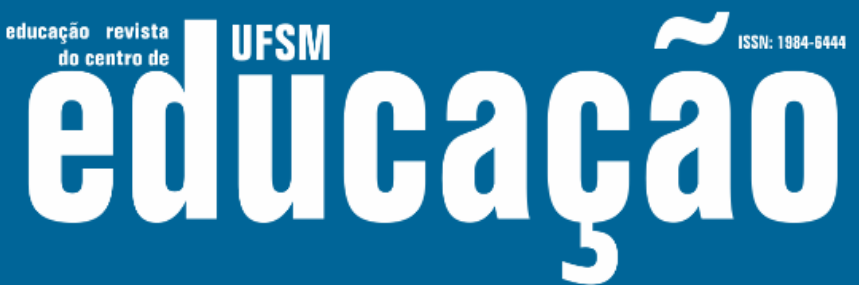

ISSN: 1984-6444 | http://dx.doi.org/10.5902/1984644437035

Assim, diante de uma sociedade global atravessada por processos contínuos de desenvolvimento tecnológico, de transformação de cadeias produtivas, necessidade constante de requalificação profissional e complexidades socioculturais das mais diversas, as novas urgências para a formação de seus membros tornam-se mais compreensíveis. Da aprendizagem como mote para o seu desenvolvimento e processos transformadores surge a necessidade de pensar nas habilidades e competências que seriam mais fundamentais de serem desenvolvidas.

Em 2012, a National Research Council, uma organização estadunidense responsável por produzir pesquisas e relatórios sobre questões sociais importantes para contribuição na criação de políticas públicas, reuniu uma equipe de especialistas de diversas áreas para apontar sob quais novos caminhos a educação dos EUA deveria avançar. Assim, o grupo de economistas, psicólogos e educadores realizou pesquisas para ajudar a vislumbrar o futuro dos estudantes no que se refere a objetivos de aprendizagem em cada ciclo escolar, capacitação profissional para as configurações atuais do mercado de trabalho e capacidades e habilidades para contribuírem para melhores condições de vida pessoal e social. O resultado deste trabalho foi a publicação do livro Education for life and work: Developing Transferable Knowledge and Skills in the 21st Century ${ }^{1}$. A proposta do documento é apresentar direções para a prática educacional, de modo a fazer os estudantes alcançarem o que denominam de transferable Knowledge, o que em português seria algo com o sentido de "conhecimento aplicável" ou "conhecimento transferível". Isto é, a capacidade de aplicar o aprendizado em situações próprias de circunstâncias da vida real. Desta forma, este seria um caminho para a educação alinhar-se mais às demandas do mundo, sendo fundamental para formar cidadãos dotados do que o documento denomina como as "competências para o século XXl". Grupos de conhecimentos, habilidades e atitudes capazes de alicerçarem saberes essenciais para o desenvolvimento humano, sejam de ordem econômica, social, cultural, política, moral, ou mesmo, artística.

"As competências do século XXl" são divididas em três grupos: competências cognitivas, competências intrapessoais e competências interpessoais. Abaixo segue um breve resumo de suas principais características: 


\section{Aithaดูão}

ISSN: 1984-6444 | http://dx.doi.org/10.5902/1984644437035

- Competências cognitivas: estratégias e processos de aprendizagem; pensamento crítico; alfabetização informacional, raciocínio e argumentação; memória e criatividade.

- Competências intrapessoais: capacidade de moldar comportamentos e inteligência emocional. Tais como flexibilidade, iniciativa, respeito, apreciação da diversidade e metacognição.

- Competências interpessoais: trabalho em equipe, colaboração e senso de liderança. Tais como colaboração, responsabilidade e resolução de conflitos.

Esse grupo de competências estabelecido pelo National Research Council ajuda a lançar luz sobre o quanto a educação tradicional está aquém das demandas da vida real. Um sistema educacional preocupado em demasia com o "acúmulo de conhecimento" e, no mais, priorizando apenas o desenvolvimento de competências cognitivas, restringe a sua eficácia. Promove um processo educacional descolado do mundo real, sobretudo, por dois fatores bastante evidentes: o sociocultural e o biológico.

A patente defesa de uma educação mais em compasso com a vida é fruto da evidência de que é preciso que ela acompanhe ou, ao menos, esteja conectada às transformações da sociedade. Um mundo assolado por mudanças contínuas, com novas tecnologias de informação e sistemas de comunicação, redesenha a todo momento as formas de interação e relacionamento. Tudo isso, inevitavelmente, demanda sistemas de formação e capacitação que dialoguem com esse contexto. Mas a necessidade de mudança na educação não se resume somente a estas exigências. $O$ avanço da ciência proporcionou o desenvolvimento de pesquisas e estudos cada vez mais minuciosos quanto aos reais mecanismos da aprendizagem. Nos últimos tempos, áreas como a Psicologia educacional e a Neurociência cognitiva têm dado grandes contribuições para o fomento de práticas educacionais que levem em conta dados científicos atualizados para os seus desenhos metodológicos. Não à toa, campos ligados ao estudo dos processos de aprendizagem, como a Psicopedagogia e a Neuropsicopedagogia, têm ganhado crescente espaço na 


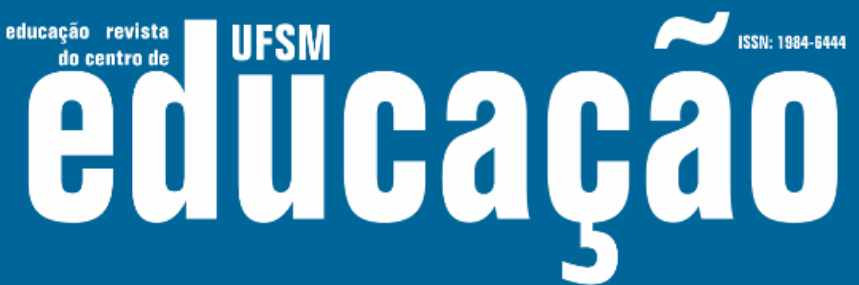

ISSN: 1984-6444 | http://dx.doi.org/10.5902/1984644437035

formação de educadores interessados nessa interface entre educação e as ciências cognitivas. Propósitos também presentes em novas áreas, como o caso da Neuroeducation ou a Brain, Mind and Education², ainda assentando seu espaço de atuação, mas, igualmente interessadas num maior intercâmbio de conhecimentos entre estudos biológicos sobre o funcionamento cerebral e práticas pedagógicas.

Assim, nas últimas décadas, foi possível notar o surgimento de importantes contribuições teóricas interessadas na tentativa de sistematizar um corpo de competências a serem aprimoradas nos sistemas educacionais através de novas configurações metodológicas. Referências como os "quatros pilares da UNESCO" e as "competências do século XXI" foram importantes para indicar os caminhos que a educação deve trilhar no século XXI. A transmutação disso em práticas pedagógicas efetivas passa a ser o desafio das iniciativas educacionais que pretendem considerar estas perspectivas como condição fundante.

\section{Deeper learning como estratégia de sistematização da "aprendizagem ativa"}

Ultimamente, muito tem se comentado sobre as cunhadas "metodologias ativas", sobretudo, no contexto educacional brasileiro. Estratégias pedagógicas como "aprendizagem baseadas em equipes", "aprendizagem baseadas em projetos", "aprendizagem baseada em problemas", "estudos de casos", "júri simulado", "aprendizagem por pares", entre outras, surgem como soluções eficazes para experiências de estudo que se pretendem mais efetivas quanto aos objetivos de aprendizagem.

O interesse por este assunto tem mobilizado professores e gestores educacionais de todos os cantos do país interessados em descobrir alternativas inovadoras cabíveis de serem implementadas em sala de aula. Formas que possam transformar a experiência educacional em algo mais atraente para os estudantes, criando circunstâncias de maior engajamento, motivação e desafios através das propostas pedagógicas. Algo que se fundamenta na concepção de que é preciso dar 


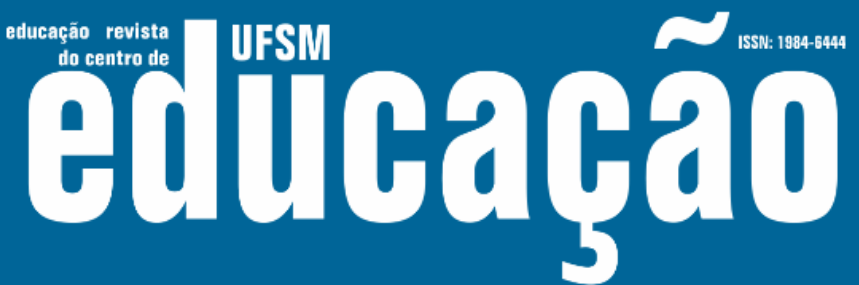

ISSN: 1984-6444 | http://dx.doi.org/10.5902/1984644437035

maior protagonismo aos educandos. Eles sim devem estar no centro da experiência de aprendizagem, e não mais o professor. Isto é uma maneira de considerar os seus pressupostos pessoais e culturais como fundamentais para o desenho de qualquer que seja a proposta pedagógica. Levar em conta os seus repertórios, interesses, anseios, experiências de vida, visões de mundo e habilidades, como pano de fundo para o planejamento das situações de aprendizagem propostas pelos professores, é tarefa quase obrigatória para educadores que desejam, de fato, proporcionar experiências de aprendizagem mais significativas, e não mais "mecânicas".

\footnotetext{
Novas ideias e informações podem ser aprendidas e retidas na medida em que conceitos, ideias ou proposições relevantes e inclusivas estejam adequadamente claros e disponíveis na estrutura cognitiva do indivíduo e funcionem, dessa forma, como "ancoradouro" para novas ideias, conceitos ou proposições. (MOREIRA, 2011, p.103)
}

Uma das ideias centrais da "teoria da aprendizagem significativa", desenvolvida pelo psicólogo estadunidense David Ausubel, sustenta que a melhor forma de proporcionar uma aprendizagem significativa é estabelecendo maiores conexões entre o conhecimento novo e os conhecimentos prévios dos educandos. A passagem de Marco Antonio Moreira (2011), estudioso de Ausubel, ressalta isto utilizando o termo "ancoradouro" como metáfora. Aquilo que já se sabe seria responsável por "ancorar" o conhecimento novo, fortalecendo o seu vínculo na memória. Uma evidência do quanto não se deve desconsiderar os repertórios cognitivos e culturais dos estudantes, muito pelo contrário. Devem ser a base para o planejamento e proposições do professor. 0 "social" enquanto ponto de partida e de chegada da educação.

Com a demanda cada vez maior pelo redesenho de suas práticas pedagógicas, educadores e instituições de ensino têm lançado mão do uso de "metodologias ativas" como meios eficazes de propiciar aos estudantes um contínuo estado de "ativação", de protagonismo. Isso fez com que a utilização do termo "aprendizagem ativa" se tornasse frequente na literatura especializada. Uma definição que se contrapõe a uma ideia de aprendizagem somente por recepção. 


\title{
T usm AutlathaO
}

ISSN: 1984-6444 | http://dx.doi.org/10.5902/1984644437035

Os estudantes aprendem tanto passivamente quanto ativamente. A aprendizagem passiva acontece quando eles exercem o papel de "receptáculos de conhecimento", isto é, não participam diretamente no processo de aprendizagem. Já aprendizagem ativa é mais propensa a acontecer quando os estudantes estão também fazendo algo, além de somente ouvir. (RYAN; MARTENS, 1989, p. 20, apud BONWELL; EISON, 1991, p. 18)

Embora a expressão "aprendizagem ativa" não tenha uma definição muito precisa na literatura educacional, é possível destacar algumas características gerais que são normalmente associadas à utilização de estratégias que promovem experiências de aprendizagem ativa nas salas de aula: os estudantes envolvem-se em atividades para além de somente ficar ouvindo professor; menos ênfase é colocada na transmissão de informação e, mais, em desenvolver as suas habilidades; os estudantes são engajados em atividades de escrita, pesquisa, discussão e colaboração; uma maior ênfase é posta na reflexão dos estudantes sobre suas próprias atitudes e valores (BONWELL; EISON, 1991). Uma tendência pedagógica crescentemente disseminada em razão da evidência da necessidade de maior dinamismo e interação nas salas de aula tradicionais. "Os estudantes devem falar, escrever e discutir sobre o que estão aprendendo. Relacionar isso a experiências passadas, visualizando e aplicando o aprendizado no seu dia a dia" (CHICKERING; GAMSON 1987, p. 3, apud BONWELL; EISON, 1991, p. 20).

\begin{abstract}
A verdadeira aprendizagem não é a memorização. A maior parte do que memorizamos se perde em questão de horas. Não se pode absorver tudo de uma vez. Para reter o que se tem estudado, os estudantes devem mastiga-lo bem. Um docente não pode fazer o trabalho mental de seus alunos, já que eles devem formar um todo significativo a partir do que escutam e veem. Sem a oportunidade de discutir, formular perguntas, fazer e talvez, também, ensinar a outra pessoa, não terá uma verdadeira aprendizagem. (SILBERMAN, 2006, p. 18)
\end{abstract}

Em suma, abordar os conteúdos programáticos de forma dinâmica, com discussões, proposições, pesquisas, resolução de problemas, consultas bibliográficas e colaboração, são estratégias que se apresentam como essenciais para esta verdadeira "ativação" dos estudantes, como ressalta Mel Silberman (2006). Uma 


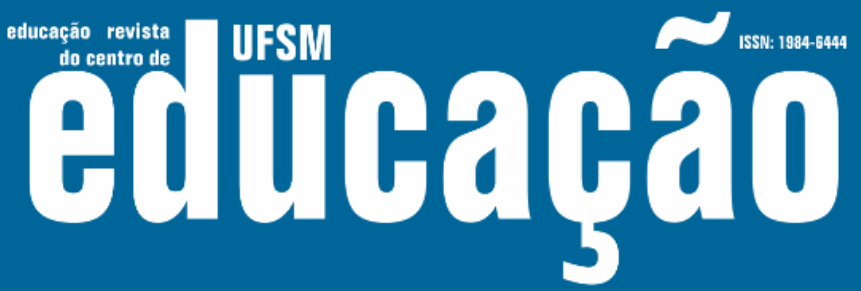

ISSN: 1984-6444 | http://dx.doi.org/10.5902/1984644437035

condição, cada vez mais, necessária de ser instaurada nas salas de aula. O que faz com que surja uma iminente demanda por uma maior sistematização da aprendizagem ativa nos currículos e projetos pedagógicos das instituições de ensino.

Desta forma, é notável uma intrínseca relação entre a almejada "ativação" do educando e a crescente discussão acerca da necessidade de os sistemas educacionais integrarem aos seus projetos pedagógicos as propaladas "competências do século XXI", enunciadas pelo National Research Council. Meio que uma enquanto consequência da outra e vice-versa. Ou seja, a demanda por se repensar os sistemas educacionais tradicionais deriva de diferentes necessidades. Em síntese, considero essas três como as mais evidentes no mundo atual: uma maior integração com o mundo do trabalho; uma maior correlação com as pesquisas e estudos científicos sobre os processos de aprendizagem; e melhores formas para se desenvolver competências que contribuam para a cidadania.

Em 2010, a William and Flora Hewlett Foundation foi responsável por apresentar o termo deeper learning ${ }^{3}$. Esta instituição estadunidense sem fins lucrativos é ligada a programas de apoio e fomento à educação, ambientalismo, desenvolvimento humano, arte e filantropia. Como forma de apoiar e contribuir para o crescente movimento de renovação das práticas pedagógicas do sistema educacional dos EUA nos últimos anos, foi apresentado a definição de deeper learning (aprendizagem aprofundada) como um conjunto de competências que os estudantes devem dominar a fim de desenvolverem um entendimento aguçado do conteúdo acadêmico, aplicando estes conhecimentos a problemas do dia a dia, seja através dos projetos de sala de aula ou situações vivenciadas no trabalho ou vida pessoal. Definição sintetizada pelo National Research council como "o processo através do qual um indivíduo se torna capaz de absorver o que aprendeu em uma situação para poder aplicar em novas situações que possam surgir", processo denominado por eles como transferable knowledge, como já citado antes.

Desta forma, para se atingir a deeper learning é necessário desenvolver seis competências-chave estabelecidas como prioridades para uma maior "ativação" do estudante. São elas: dominar conteúdos acadêmicos centrais; pensar criticamente e 


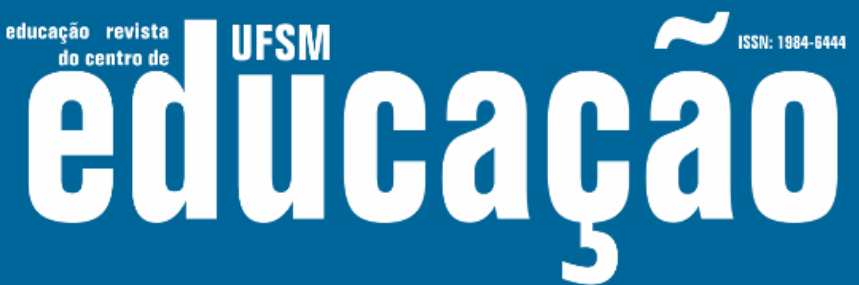

ISSN: 1984-6444 | http://dx.doi.org/10.5902/1984644437035

resolver problemas complexos; trabalhar colaborativamente; comunicar-se de forma eficaz e efetiva; aprender a aprender; e desenvolver a mentalidade acadêmica.

"Dominar conteúdos acadêmicos centrais" está relacionado a compreender conceitos, teorias e informações dos diferentes campos do conhecimento, tendo a capacidade de aplicá-los a fatos e situações do mundo real. "Pensar criticamente e resolver problemas complexos" refere-se a utilizar ferramentas e técnicas reflexivas para formular e resolver problemas, tais como: análise de dados, raciocínio estatístico, investigação científica, criatividade, pensamento não-linear e persistência. "Trabalhar colaborativamente" é saber cooperar com os colegas para completar tarefas e ter sucesso na resolução de problemas, e saber comunicar-se e considerar diferentes pontos de vista para o planejamento e alcance dos objetivos do trabalho em equipe. "Comunicar-se de forma eficaz e efetiva" trata da organização de seus dados, descobertas e pensamentos, para uma capacidade de se expressar que seja significativa, construtiva e apropriada para diferentes situações e audiências. "Aprender a aprender" é monitorar e saber direcionar sua própria aprendizagem, autonomia, independência e autorreflexão sobre a eficácia e pertinência de seus estudos. E "desenvolver a mentalidade acadêmica", que é uma competência ligada à capacidade do estudante de planejar e sistematizar seus objetivos de estudo, analisando conclusões, atingindo objetivos, desenvolvendo trabalhos com critérios e buscando soluções para superar obstáculos; algo ligado ao desenvolvimento de uma mentalidade científica.

Esse grupo de competências surgiu como necessidade para se organizar as demandas da educação do século XXI. É uma proposta de organização e sistematização das práticas pedagógicas, levando-se em conta a urgência por uma aprendizagem mais ativa e em compasso com seu tempo. Apontando caminhos para o desenvolvimento de metodologias, abordagens e estratégias de ensino que possam contribuir para uma forma de fazer educação que tenha em seu horizonte experiências cada vez mais promotoras de pensamento, colaboração, criatividade, engajamento e autonomia. 


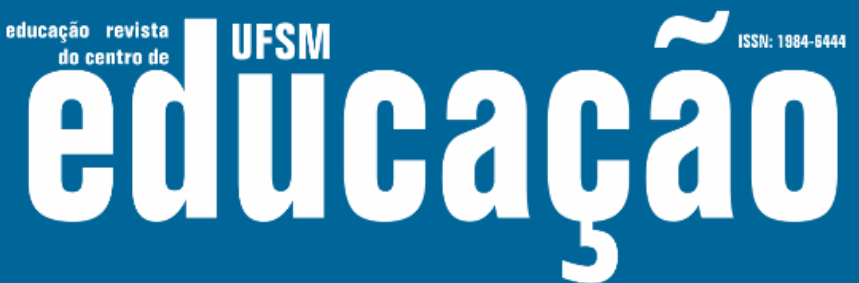

ISSN: 1984-6444 | http://dx.doi.org/10.5902/1984644437035

\section{Considerações finais}

O diagnóstico acerca do caráter global das sociedades desenvolvidas e emergentes traz a evidência de que as formas de viver vão modificando-se com o tempo. As maneiras de se pensar e se relacionar passaram a ser influenciadas por uma realidade que, crescentemente, tem deixado clara a dimensão de sua complexidade. Se há 50 anos o mundo era muito diferente do que é hoje em dia, há de pressupor-se que os indivíduos também acompanharam esse processo transformativo. E falar em transformação é falar em formação. E falar em formação é falar em educação. Como a educação relaciona-se com essas mudanças? Sabe-se que a resposta para esta pergunta traz a evidência de que algo é preciso ser feito de forma diferente do que a educação tradicional oferece. O papel cumprido outrora, responsável por democratizar o acesso à educação, e também criar um sistema de formação em larga escala, já não atende às demandas do contexto atual. A facilidade e a velocidade de acesso a informações contribuíram para o surgimento de uma circunstância em que tudo é mais transitório, mais efêmero.

Iniciativas como as da UNESCO e também da National research council são importantes para lançarem luz sobre indícios inevitáveis quanto aos caminhos que a educação deve seguir. Vive-se em um mundo diferente daquele dos séculos passados, a iminência da relação educação/trabalho nunca foi tão necessária de ser pensada como atualmente.

\footnotetext{
Um dos grandes problemas da estruturação da pedagogia no século $X X$ surgiu com o advento e, depois, com a crise do "mundo do trabalho". Até o início do século XVIII não tínhamos uma "sociedade do trabalho" como viemos conhecê-la nos séculos XIX e XX. Portanto, quando surgiram as primeiras pedagogias modernas, o trabalho livre, industrial e comercial, como conhecemos hoje, não era algo que conduzia todos na sociedade. A parte letrada da sociedade não trabalhava. Ou, ao menos, não trabalhava segundo nosso entendimento moderno de "trabalho". (GHIRALDELLI JR, 2007, p49).
}

A passagem acima de Paulo Ghiraldelli Jr (2007) é precisa quanto às mudanças de concepção sobre a relação "educação e mundo do trabalho" quando pensadas sob o ponto de vista histórico. De fato, é uma emergência que também 


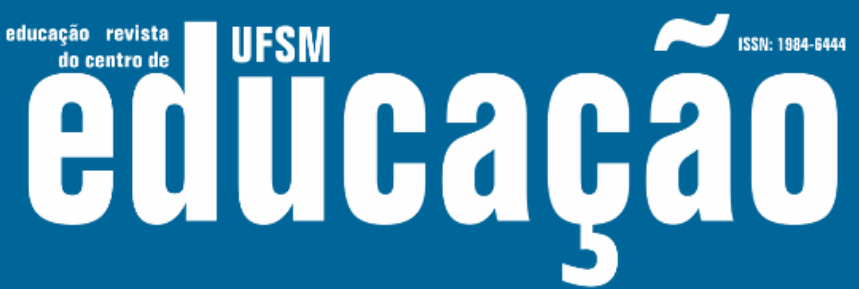

ISSN: 1984-6444 | http://dx.doi.org/10.5902/1984644437035

nos faz repensar, de maneira mais ampla, os objetivos norteadores de uma educação que se pretende ressignificada.

Propostas como a enunciada pelo conceito de deeper learning, e seus grupos de competências-chave contribuem para tentativas de maior aproximação entre as práticas pedagógicas e o mundo real. É um conceito que propõe uma sistematização sobre a concepção, cada vez maior, acerca da premência de uma sala de aula que "ative" os estudantes. Desta forma, deeper learning, embora um termo ligado à ideia de aplicação dos conhecimentos em situações do mundo real, num processo denominado como transferable knowledge, em síntese, estabelece uma tentativa de estruturação para a prática daquilo que comumente tem sido denominado nos meios acadêmicos como "aprendizagem ativa". Sugere uma base para que as novas metodologias e abordagens educacionais possam fundamentar suas ferramentas pedagógicas.

Assim, nota-se que este é um caminho educacional que tem a sua evidente potência não apenas em razão de uma maior adequação às urgências do mundo produtivo, do trabalho. Mas, sobretudo, uma alternativa também capaz de atuar de forma eficaz sobre demandas ligadas à formação do cidadão. Especialmente, um cidadão que possa colocar em prática competências desenvolvidas, seja em escolas ou universidades, capazes de munir os estudantes de qualidades relacionais e convivais das mais importantes e urgentes. Principalmente, quando vemos que a "globalidade do mundo", evidencia também uma "globalidade da vida" em sua totalidade. Um estudante dotado de competências intrapessoais e interpessoais estará muito mais preparado para lidar com urgências sociais que perpetuam visões totalizadoras, fundamentalismos incondicionais, intolerância, preconceito, racismo, exclusão, a miséria humana em todas as suas dimensões. "Ativar" os alunos é, acima de tudo, ativar a nossa esperança em fazer da educação o melhor caminho para um mundo melhor. 


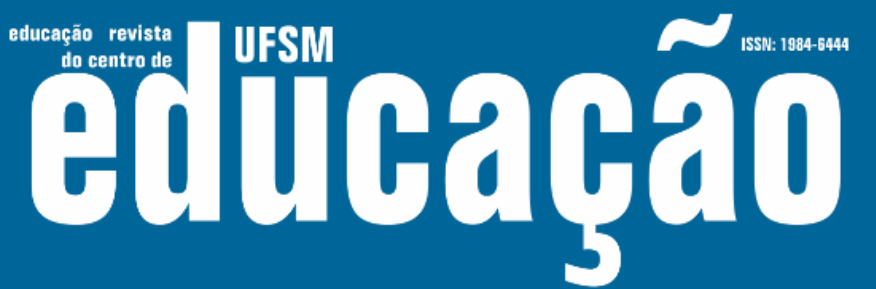

ISSN: 1984-6444 | http://dx.doi.org/10.5902/1984644437035

\section{Referências}

BELL, D. O advento da sociedade pós-industrial: uma tentativa de previsão social. São Paulo: Cultrix, 1973.

BONWELL, Charles; EISON, James. Active Learning: Creating excitement in the Classroom. Washington: The George Washington University, 1991.

CASTELLS, M. (2000). A era da informação: economia, sociedade e cultura. A sociedade em rede. 3. ed. v. I. São Paulo: Paz e Terra.

DRUCKER, P. (1976). Uma era de descontinuidade: orientações para uma sociedade em mudança. 3. ed. Rio de Janeiro: Zahar Editor.

USA. CISCO Public Information. The Learning Society. 2010

USA. National Research Council. Education for Life and Work: Developing Transferable Knowledge and Skills in the 21st Century. Washington DC, 2012.

Fischer, G (2000). Lifelong Learning - More than training. In: Journal of Interactive Learning Research, Vol. 11 Issue (3/4), pp. 285- 29

GHIRALDELLI JR, Paulo. O que é pedagogia. São Paulo: Brasiliense, 2007.

GIOVANINI, Adilson; AREND, Marcelo. Contribution of services to economic growth: kaldor's fifth law? RAM, Rev. Adm. Mackenzie, August 2017, vol.18, no.4, p.190-213.

HARGREAVES, Andy. O Ensino na Sociedade do Conhecimento - a educação na era da insegurança. Porto: Porto Editora, 2004.

LANE, R. E. (1966). The decline of politics and ideology in a knowledgeable society. American Sociological Review, v.21, n.5. p.649-662

FRANCE. Learning: the treasure within; report to UNESCO of the International Commission on Education for the Twentyfirst Century (highlights). Paris: UNESCO, 1996.

MCLUHAN, Marshall; FIORE, Quentin. Guerra e paz na aldeia global. Rio de Janeiro: Record, 1971.

MOREIRA, Marco Antonio. Aprendizagem significativa: a teoria e textos complementares. São Paulo: Editora Livraria da Física, 2011. 


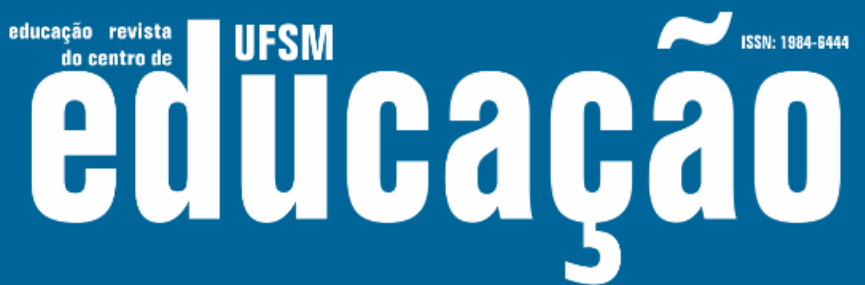

ISSN: 1984-6444 | http://dx.doi.org/10.5902/1984644437035

MORIN, Edgar; DÍAZ, Carlos Jesús Delgado. Reinventar a educação - abrir caminhos para a metamorfose da humanidade. São Paulo: Palas Athena, 2016.

SCOZ, Beatriz. Psicopedagogia e realidade escolar: o problema escolar e de aprendizagem. 2 ed. Petrópolis, RJ: Vozes. 1994.

SILBERMAN, Mel. Aprendizaje activo: 101 estrategias para enseñar cualquier tema. Buenos Aires: Editorial Troquel, 2006.

\section{Notas}

${ }^{1}$ https://www.nap.edu/catalog/13398/education-for-life-and-work-developingtransferable-knowledge-and-skills

${ }^{2}$ Neuroeducation e Mind, brain and education têm os dois termos utilizados para definir um novo campo interdisciplinar que tem surgido, com o propósito de construir conexões entre a Neurociência, Ciências cognitivas, Psicologia e educação, de maneira a criar uma nova ciência da aprendizagem capaz de contribuir para as práticas educacionais.

${ }^{3}$ William and Flora Hewlett Foundation. (2013). Deeper learning competencies.

Disponível em: http://www.hewlett.org/library/hewlett-foundation-publication/deeper-learningdefined

\section{Correspondência}

Bruno Gomes de Almeida - Rua Braz Bernardino, 105, Centro, CEP: 36010-320, Juiz de fora, Minas Gerais, Brasil.

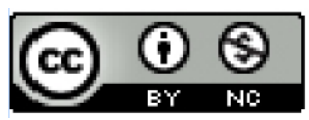

This work is licensed under a Creative Commons Attribution-NonCommercial 4.0 International (CC BY-NC 4.0) 